\title{
Respiratory Epithelial Cells as Master Communicators during Viral Infections
}

\author{
Tanya A. Miura ${ }^{1}$ \\ Published online: 13 February 2019 \\ (C) Springer Nature Switzerland AG 2019
}

\begin{abstract}
Purpose of Review Communication by epithelial cells during respiratory viral infections is critical in orchestrating effective antiviral responses but also can lead to excessive inflammation. This review will evaluate studies that investigate how respiratory epithelial cells influence the behavior of immune cells and how epithelial cell/immune cell interactions contribute to antiviral responses and immunopathology outcomes.

Recent Findings Previous studies have characterized cytokine responses of virus-infected epithelial cells. More recent studies have carefully demonstrated the effects of these cytokines on cellular behaviors within the infected lung. Infected epithelial cells release exosomes that specifically regulate responses of monocytes and neighboring epithelial cells without promoting spread of virus. In contrast, rhinovirus-infected cells induce monocytes to upregulate expression of the viral receptor, promoting spread of the virus to alternate cell types. The precise alteration of PDL expression on infected epithelial cells has been shown to switch between inhibition and activation of antiviral responses.

Summary These studies have more precisely defined the interactions between epithelial and immune cells during viral infections. This level of understanding is critical for the development of novel therapeutic strategies that promote effective antiviral responses or epithelial repair or inhibit damaging inflammatory responses during severe respiratory viral infections.
\end{abstract}

Keywords Respiratory syncytial virus · Influenza A virus $\cdot$ Rhinovirus $\cdot$ Airway epithelial cells

\section{Introduction}

The epithelial cells that line the respiratory tract constitute a vast surface area that is vulnerable to infection by pathogens, including many strains of viruses from different families. Respiratory viral infections result in diseases ranging from the common cold to bronchiolitis to pneumonia and acute respiratory distress. Viruses are the most commonly detected pathogens in adults with community-acquired pneumonia, with rhinoviruses and influenza viruses accounting for the highest prevalence of cases [1]. Human metapneumovirus, respiratory syncytial virus, parainfluenza viruses, and coronaviruses are also significant causes of pneumonia in adults [1]. Children experience an

This article is part of the Topical Collection on Virology

Tanya A. Miura

tmiura@uidaho.edu

1 Department of Biological Sciences and Center for Modeling Complex Interactions, University of Idaho, Moscow, ID 83844, USA average of one to four respiratory infections per year [2], with rhinoviruses, respiratory syncytial virus, and influenza viruses being the most common viruses detected, regardless of disease severity [3]. Although there is not a one-size-fits-all immune response that is effective against respiratory viral infections, one key factor is to induce effective antiviral responses while limiting immune-mediated pathology [4-6]. While a robust response is needed to limit viral spread to the lower respiratory tract and clear the infection, excessive inflammation and destruction by cytotoxic cells leads to immunopathology. The epithelial cells that line the respiratory tract are critical for effecting this balance during viral infection.

Airway and alveolar epithelial cells are targets for viral infection, including rhinoviruses, influenza viruses, coronaviruses, and pneumoviruses. Rhinovirus antigens have been found in epithelial cells of the upper respiratory tract and the bronchi of experimentally infected subjects [7]. Viral antigens have been detected in alveolar type I (AT1) and type II (AT2) epithelial cells in the lungs of patients with fatal infections by influenza A viruses (IAV), respiratory syncytial virus (RSV), and coronaviruses [8-13]. Infected epithelial cells play a key role in 
signaling innate cellular antiviral responses, orchestrating responses by myeloid and lymphoid cells, and promoting epithelial repair. This review will focus on recent studies that demonstrate the versatile communication that respiratory epithelial cells have with other cells and how this affects immune responses and pathogenesis during respiratory viral infections.

\section{Epithelial Cell Responses to Viral Infections}

Epithelial cells that span the length of the respiratory tract from the nasal to alveolar compartments respond to viral infection by producing cytokines and chemokines that communicate with immune cells to activate and regulate antiviral responses. Primary cultures of airway and alveolar epithelial cells are an invaluable system for characterizing the response of highly differentiated epithelial cells to viral infections. Highly differentiated cultures of primary human nasal epithelial cells are susceptible to rhinovirus replication, predominantly in ciliated cells [14]. Innate immune sensing (TLR7, RIG-I) and effector molecules (type I and III interferons), and proinflammatory chemokines (CXCL-9, 10, 11, and CCL5) are expressed by infected nasal epithelial cells [14]. IAV induces a similar innate response in primary nasal $[15,16]$, bronchial [17], and alveolar [18, 19] epithelial cells. Coronaviruses are more restrictive in the epithelial cell types that they replicate in in vitro [20-24]. In primary human AT2 cells, human coronavirus HKU1 induces expression of type III IFN, CXCL10, and CCL5 [23]. The highly pathogenic human coronaviruses, MERS-CoV and SARS-CoV, induce reduced or delayed expression of cytokines in a human lung epithelial cell line, which is thought to be due to avoidance of recognition by innate receptors in the infected cell $[25,26]$. RSV infection of well-differentiated pediatric bronchial epithelial cells induces secretion of chemokines that are also detected in infants with severe RSV disease, including IL-6, CCL5, CXCL8, and CXCL10 [27, 28]. Mouse models of differentiated respiratory epithelial cells recapitulate many of these findings and can be used as a widely available and tractable system in which to understand epithelial responses to respiratory viral infections [24, 29].

When gene expression responses to different respiratory viruses have been compared side-by-side, shared and virusspecific patterns emerge [16, 17, 30, 31]. A direct comparison of the response of primary human tracheobronchial epithelial cells to RSV and IAV infections demonstrated that IAV induces a much stronger response; however, shared gene expression signatures include type I interferon (IFN) and IFNinduced chemokines, including CXCL-9, 10, 11, and 8 and CCL5 [17]. Similarly, wild-type IAV and the matched live attenuated influenza vaccine induce similar gene expression responses in cultures of primary human nasal epithelial cells, though the vaccine strain induces a more robust response [16].
Although IAV and rhinovirus induce unique gene expression signatures, genes involved in viral detection, type I IFN responses, and cytokine and chemokine genes have shared upregulation by the two unrelated viruses in human bronchial epithelial cells and a mouse lung cell line [30, 31].

A large number of studies have characterized gene expression responses of respiratory epithelial cells to viral infections in vitro. Fewer studies have demonstrated the contribution of these responses to the overall response to respiratory viral infection within the lungs. Stegemann-Koniszewski et al. analyzed gene expression in purified AT2 cells from IAVinfected mice compared to mRNA from whole lung tissue. They found that AT2 cells make a significant contribution to gene expression responses in the lungs of IAV-infected mice [32••]. While several chemokines had increased expression in AT2 cells upon IAV infection, expression of CXCL5 and CCL5 was induced higher in AT2 cells than the whole lung tissue. The robust gene expression response of AT2 cells in vivo suggest that these cells are not only responding directly to viral infection, but are also responding to signals from cells in their environment. Co-culture systems that evaluate the responses of AT2 cells to viral infection in the context of the other cell types within the lung during infection are critical to understand the response of AT2 cells to environmental cues during infection. A complementary approach in which cytokine expression was evaluated in alveolar macrophages in response to RSV infection ex vivo compared to cytokines expressed early in RSV-infected lung tissues identified a set of cytokines that are likely to be expressed by epithelial cells and not alveolar macrophages [33].

Immune cells that infiltrate the respiratory tract upon viral infection also contribute to cytokine responses and serve to amplify and/or skew immune responses during infection. Cell depletion studies demonstrate the contribution of immune cells to amplifying cytokine responses, but can be misleading due to compensation by other cell types in the lungs. Depletion of inflammatory monocyte-macrophages in a mouse model of SARS-coronavirus infection results in a significant reduction of TNF- $\alpha$, IL-6, and CCL2 in the airways [34]. Mice that were humanized with $\mathrm{T}$ and $\mathrm{B}$ cells have increased human, but not mouse, CCL3 and IL-1 $\beta$ in the lungs upon infection by RSV [35•]. This suggests that these cytokines are being produced by the reconstituted immune cells and not the respiratory epithelium of the mouse.

IFN- $\beta$ is expressed early upon viral infection and is critical for stimulating expression of other type I IFNs, inducing innate antiviral gene expression, and orchestrating adaptive immune responses [36-39]. A novel IFN- $\beta$ reporter mouse that expresses luciferase from the IFN- $\beta$ promoter was used to demonstrate the cell-type specificity of IFN- $\beta$ production upon influenza virus infection [40•]. Infection of the reporter mice with wild-type IAV restricted IFN- $\beta$ response to nonepithelial cells, as the virus antagonized the IFN response in 
infected epithelial cells. However, upon infection by a mutant virus that does not express IFN antagonist, IFN- $\beta$ was expressed by infected epithelial cells and virus antigenpositive macrophages [40•]. In a mouse model of SARScoronavirus infection, IFN- $\beta$ is expressed predominantly by airway epithelial cells and plasmacytoid dendritic cells [34]. The early production of IFN- $\beta$ by virus-infected epithelial cells is likely important for communicating with uninfected cells as well as immune cells.

\section{Epithelium/Macrophage Communication}

Resident alveolar macrophages (AM) are non-migratory cells that maintain alveolar homeostasis through direct interactions with the alveolar epithelium. Communication between AM and alveolar epithelial cells is bi-directional, occurring through cell surface receptors, gap junctional channels, release and uptake of secreted microparticles, and cytokine signaling [41, 42]. During homeostasis, epithelial cells provide inhibitory signaling to prevent activation of AM in the airspaces. Upon viral infection, this anti-inflammatory signaling is overcome to promote initiation of antiviral immune responses. AM can contribute to protection or pathology during viral infection, depending on the virus. Depletion of AM from mice prior to inoculation with RSV or IAV worsens disease, but lessens the severity of metapneumovirus or SARS-coronavirus infections [43-46]. In the case of SARS-coronavirus infection in mice, AM have an inhibitory influence on dendritic cell activation and the subsequent development of T cell responses [46].

Co-culture of mouse AM with IAV-infected epithelial cells has demonstrated that AM phagocytose infected epithelial cells [47•]. AM also produce hepatocyte growth factor in response to IAV-infected epithelial cells, which induces proliferation of alveolar epithelial cells to repair epithelial damage [47•]. Cardani et al. showed that AM protect AT1 cells from IAV infection by inhibiting leukotriene D4 [48••]. AT1 cells of mice that are deficient specifically in alveolar macrophages, but not other myeloid cell types, have increased susceptibility to IAV. Furthermore, inhibition of the cysteinyl leukotriene receptor 1 in alveolar macrophage-deficient mice reversed this enhanced susceptibility phenotype [48••]. This suggests that, beyond direct clearance of IAV, alveolar macrophages provide signals that protect AT1 cells from infection.

In addition to resident AM, monocyte-macrophages are recruited to the lungs during viral infection. RSV infection of human bronchial epithelial cells induces expression of chemokines including RANTES, which is specifically responsible for chemotaxis of monocytes and eosinophils toward infected epithelial cells [49]. These co-culture studies have further showed that upon interaction of the monocytes and eosinophils with infected epithelial cells, there is additional production of chemokines by these leukocytes, providing positive feedback on chemokine production. More recently, Chahar et al. demonstrated that exosomes released from RSV-infected epithelial cells stimulate chemokine production by monocytes [50••]. Although the mechanism of monocyte activation is not known, exosomes are not able to spread RSV to uninfected cells. In addition to viral proteins and RNA, exosomes released from infected cells contain increased proportions of host small regulatory RNAs [50••], which may manipulate gene expression in nearby uninfected cells.

Airway epithelial cells have been shown to promote rhinovirus infection of monocytes [51••]. Although cultured monocytes are not permissive to rhinovirus infection [52], co-culture of monocytes with epithelial cells enhances infection in the monocytes [51••]. Interestingly, enhancement of monocyte susceptibility to rhinovirus infection is not dependent upon infection of the epithelial cells, as conditioned medium from uninfected epithelial cells also promotes this effect. Epithelial cells were shown to upregulate ICAM-1 on the monocytes and thus mediate susceptibility to major serogroup rhinoviruses that use ICAM-1 to enter cells. Thus, monocyte infection may occur in the context of epithelial cells in vivo. As active replication of rhinovirus in monocytes leads to higher production of inflammatory cytokines, if this mechanism occurs in vivo, it may contribute to enhanced inflammation during rhinovirus infection.

Programmed death-1 (PD-1) is a receptor on myeloid and lymphoid cells and signals downregulation of immune responses through its ligands, PD-L1 and PD-L2. PD ligands are expressed on airway epithelial cells and are increased upon infection by viruses including RSV, IAV, and rhinovirus [53••, $54 \bullet \bullet, 55,56]$. Oumona et al. showed that uninfected epithelial cells suppress the activity of LPS-stimulated monocytes in coculture conditions [57••]. Interestingly, RSV-infected epithelial cells lose the ability to suppress monocyte activation while increasing expression of PD-L1 [57••]. Thus, viral infection provides an as yet unknown override that allows for monocyte activation in the presence of PD-L1 signaling.

\section{Epithelium/Dendritic Cell Communication}

Lung-resident dendritic cells (DCs), identified by expression of CD103, are basolateral to and form tight junctions with airway epithelial cells [58]. Signaling form the epithelial cells is critical for maintaining tolerogenic CD103+ DC homeostasis. Upon viral infection, epithelial cells stimulate DCs to acquire viral antigens and migrate to lymph nodes to activate CD8+ T cell responses [59-61]. Co-culture of myeloid DC with airway epithelial cells results in dramatic changes in gene expression by the DC, compared to culture of DC in isolation [62]. While the co-cultured DC have both increased and decreased expression of various chemokines, genes involved in pathogen recognition were consistently upregulated, suggesting that the epithelial cells signal DC to be on alert for 
infection prior to stimulation. Cytokines made by infected epithelial cells can also impact the polarity of DC-induced helper $\mathrm{T}$ cell responses by promoting either antiviral $\mathrm{T}_{\mathrm{H}} 1$ responses or allergic $\mathrm{T}_{\mathrm{H}} 2$ responses [63]. Upon activation, DC produce high levels of proinflammatory cytokines and chemokines and thus can also contribute to immunopathology in the lungs $[62,64]$.

Granulocyte-monocyte colony stimulating factor (GMCSF) contributes to survival and reduced lung damage during IAV infection [65••, 66-68]. Adoptive transfer experiments between wild-type and $G m-c s f-/-$ mice demonstrated that AT2 cells are the major cell type that produce GM-CSF during IAV infection and epithelial cell-produced GM-CSF contributes to disease attenuation and survival [65••]. GM-CSF has multiple functions that could contribute to reducing disease severity, including inducing proliferation and activation of alveolar macrophages [68, 69], downregulation of macrophage proinflammatory functions [66], activation of CD103+ DCs [65••], and repair of damaged epithelium [70]. Although enhanced GM-CSF production increases the numbers of both alveolar macrophages and DCs in the lungs of IAV-infected mice, depletion of alveolar macrophages does not substantially affect GM-CSF-mediated protection [65••]. In contrast, depletion of lung DCs reversed GM-CSFmediated protection from IAV-induced mortality [65••]. This study suggests that epithelial cell-derived GM-CSF exerts protection from IAV pneumonia in mice through DC activation, which is required for an effective CD8+ T cell response.

\section{Epithelium/Neutrophil Communication}

Neutrophils are recruited to sites of infection by respiratory viruses and can be important for antiviral responses but also contribute to immune-mediated pathology in the respiratory tract. Neutrophils predominate the airway infiltrates of RSVinfected humans and in humanized immune system mice that mimic the pathology of severe RSV infections [35•, 71, 72]. Upon stimulation by RSV, neutrophils release neutrophil extracellular traps (NETs) that inhibit infection of epithelial cells [73]. Despite this potential protective role, the presence of NETs in the airways corresponds with severe disease in RSV-infected children and in calves infected with bovine RSV [73], likely through airway obstruction.

Neutrophil chemotactic cytokines are produced by epithelial cells in response to respiratory viral infections. Our lab and others have shown that epithelial cells directly regulate neutrophil functions. Rat coronavirus infection of AT1 cells induces expression and secretion of CXC chemokines [74], which signal through CXCR2 on neutrophils to promote their recruitment and activation. Furthermore, medium from rat coronavirus-infected AT1 cells directs neutrophil chemotaxis in vitro through CXC chemokines and CXCR2-dependent signaling [75••]. In addition to chemotaxis, medium from coronavirus-infected AT1 cells also inhibits spontaneous and TNF $\alpha$-induced apoptosis of neutrophils, which is partially dependent on CXCR2 signaling [75••]. Thus, coronavirusinfected epithelial cells not only promote recruitment of neutrophils to the respiratory tract, but also may contribute to prolonging their lifespan within infected lung tissue. These functions may have opposing effects during rat coronavirus infection. Depletion of neutrophils early during rat coronavirus infection enhances disease severity and prolongs viral infection, demonstrating their contribution to an effective immune response [76]. However, the presence of neutrophils late during infection corresponds with the presence of gross and histological lesions and increased epithelial permeability [76]. Thus, their maintained presence due to inhibition of apoptosis may contribute to disease pathology.

A recent study using a co-culture system demonstrated that RSV-infected epithelial cells direct neutrophil transmigration through the epithelial monolayer [77••]. Neutrophils that transmigrate through the epithelium upregulate expression of activation markers CD11b and myeloperoxidase, while nonmigrated neutrophils also express myeloperoxidase in response to chemokines from the RSV-infected epithelial cells. Furthermore, transmigration of neutrophils through RSVinfected epithelial monolayers caused increased damage to the epithelial cells compared to neutrophil transmigration in response to fMLP [77••]. Thus, RSV-infected epithelial cells direct neutrophil migration and activation, which enhances damage to the epithelial barrier. Extensive neutrophilic inflammation is seen in children with severe RSV-induced bronchiolitis $[71,72]$. Communication between the infected epithelium and neutrophils likely contributes to this severe disease.

Additional cytokines contribute to neutrophil recruitment and activation, including basic fibroblast growth factor 2 (FGF2). In mice, bronchial and alveolar epithelial cells are responsible for the majority of FGF2 production induced by IAV infection [78]. Furthermore, depletion of FGF2 in infected mice increases the severity of disease [78]. The primary role of FGF2 in this system is to promote neutrophil chemotaxis and activation, which is needed for survival [78]. While FGF2 has many functions that could contribute to protection, disease severity was reduced when neutrophil recruitment to the lungs of FGF2 deficient animals was restored. Furthermore, treatment of a lethal IAV infection with recombinant FGF2 was effective, but not in mice that had been depleted of neutrophils. This suggests that the protective effects of epithelial FGF2 in this mouse model of IAV infection are due primarily to neutrophil recruitment.

\section{Epithelium/Lymphocyte Communication}

While a majority of studies focus on interactions between respiratory epithelial cells and innate immune cells, a few 
studies have reported interactions between the respiratory epithelium and lymphocytes. Cytokines and chemokines produced by infected epithelial cells recruit, activate, and orchestrate the functions of $\mathrm{T}$ lymphocytes. Thymic stromal lymphopoietin (TSLP) is expressed by RSV-infected airway epithelial cells, and TSLP levels correspond with $\mathrm{T}_{\mathrm{H}} 2$ cytokine production and the development of allergic asthma [79, $80 \bullet$. Enhanced TSLP production by bronchial epithelial cells in response to viral infection is a proposed mechanism of asthma exacerbation [80•*]. As described above, PD-1 ligands are expressed by virus-infected epithelial cells and, in addition to regulating monocyte functions, can affect $\mathrm{CD} 8+\mathrm{T}$ cell functions during RSV infection. Co-culture of RSV-infected bronchial epithelial cells with $\mathrm{CD} 8+\mathrm{T}$ cells promotes their activation [54••]. However, inhibition of PD-L1 signaling in this system increases $\mathrm{T}$ cell effector functions, including IFN- $\gamma$, IL-2, and granzyme B expression and concomitantly decreases viral loads in the epithelial cells [54••]. IAV has also been shown to upregulate PD-L1 expression in human airway epithelial cultures [53・*]. Further, IAV-induced expression of PD-L1 is dependent on type I IFN signaling in mouse tracheal epithelial cultures and thus may represent a generalized response to viral infection [53*0]. Similar to the studies with RSV, inhibition of PD-1 signaling during IAV infection enhances $\mathrm{CD} 8+\mathrm{T}$ cell functions in a co-culture model and in the airways of infected mice [53・0]. Thus, by increasing expression of PD-L1 by epithelial cells, viruses downregulate the effector functions of $\mathrm{CD} 8+\mathrm{T}$ cells, thereby promoting viral replication.

During RSV infection, alveolar and bronchial epithelial cells are a source of B cell-stimulating molecules, BAFF and APRIL, which promote production of IgM and IgA by airway B cells $[81 \bullet \bullet, 82]$. Thus, during RSV infection, infected epithelial cells promote a $\mathrm{T}$ cell-independent antibody response, which is important for protection against reinfection.

\section{Communication Back to Epithelial Cells}

In addition to sending information to other cell types, epithelial cells receive signals from other cells in the lungs, which is important for repair of damaged epithelium at the resolution phase of viral infections. As described above, GM-CSF is secreted by alveolar epithelial cells upon viral infection and also in response to TNF- $\alpha$ produced by stimulated alveolar macrophages [65••, 70]. GM-CSF promotes proliferation of AT2 cells, which leads to repair of damaged epithelium and restoration of its barrier functions [70]. Keratinocyte growth factor (KGF) promotes proliferation of AT2 cells and is protective against alveolar damage $[83,84]$. IL- $1 \beta$ secreted by epithelial cells stimulates production of KGF by fibroblasts, which enhances susceptibility of AT2 cells to IAV infection [85]. The production of growth factors while virus is still replicating in the lungs may worsen disease, while their stimulation of AT2 cell division would promote repair of epithelial damage. Thus, the timing of growth factor expression may be critical for repair vs. pathogenesis during respiratory viral infection. Macrophages that have been stimulated by IAVinfected epithelial cells provide signaling back to the epithelial cells that results in inhibition of Na, K-ATPase, and thus fluid absorption by epithelial cells [86•*]. This results in fluid accumulation in the alveoli and contributes to pathogenesis. Immune cells can also provide positive feedback to epithelial cells to amplify responses. For example, interferon signaling by monocytes stimulate the production of CXCL10 by bronchial epithelial cells during rhinovirus infection [87••].

\section{Conclusions}

In recent years, studies that evaluate communication between virus-infected epithelial cells and immune cells have provided a wealth of information about how the epithelium can alter the behavior of other cells during infection and vice versa. These findings are critical to develop novel therapeutic strategies that exploit communication to promote effective responses, or inhibit communication that leads to immunopathology during severe respiratory viral infections.

Acknowledgements T.A. Miura is supported by P20GM104420 from the National Institute of General Medical Sciences of the National Institutes of Health.

\section{Compliance with Ethical Standards}

Conflict of Interest Dr. Miura reports grants from NIH/NIGMS, during the conduct of the study.

Human and Animal Rights and Informed Consent This article does not contain any studies with human or animal subjects performed by any of the authors.

Publisher's Note Springer Nature remains neutral with regard to jurisdictional claims in published maps and institutional affiliations.

\section{References}

Papers of particular interest, published recently, have been highlighted as:

- Of importance

•- Of major importance

1. Jain S, Williams DJ, Arnold SR, Ampofo K, Bramley AM, Reed C, et al. Community-acquired pneumonia requiring hospitalization among U.S. children. N Engl J Med. 2015;372:835-45.

2. Fairchok MP, Martin ET, Chambers S, Kuypers J, Behrens M, Braun LE, et al. Epidemiology of viral respiratory tract infections 
in a prospective cohort of infants and toddlers attending daycare. $\mathrm{J}$ Clin Virol. 2010;49:16-20.

3. Tregoning JS, Schwarze J. Respiratory viral infections in infants: causes, clinical symptoms, virology, and immunology. Clin Microbiol Rev. 2010;23:74-98.

4. Newton AH, Cardani A, Braciale TJ. The host immune response in respiratory virus infection: balancing virus clearance and immunopathology. Semin Immunopathol. 2016;38:471-82.

5. Channappanavar R, Perlman S. Pathogenic human coronavirus infections: causes and consequences of cytokine storm and immunopathology. Semin Immunopathol. 2017;39:529-39.

6. Brandes M, Klauschen F, Kuchen S, Germain RN. A systems analysis identifies a feedforward inflammatory circuit leading to lethal influenza infection. Cell. 2013;154:197-212.

7. Mosser AG, Vrtis R, Burchell L, Lee WM, Dick CR, Weisshaar E, et al. Quantitative and qualitative analysis of rhinovirus infection in bronchial tissues. Am J Respir Crit Care Med. 2005;171:645-51.

8. Ye J, Zhang B, Xu J, Chang Q, McNutt MA, Korteweg C, et al. Molecular pathology in the lungs of severe acute respiratory syndrome patients. Am J Pathol. 2007;170(2):538-45.

9. Nicholls JM, Butany J, Poon LL, Chan KH, Beh SL, Poutanen S, et al. Time course and cellular localization of SARS-CoV nucleoprotein and RNA in lungs from fatal cases of SARS. PLoS Med. 2006;3:e27.

10. Johnson JE, Gonzales RA, Olson SJ, Wright PF, Graham BS. The histopathology of fatal untreated human respiratory syncytial virus infection. Mod Pathol. 2007;20:108-19.

11. Shieh W-J, Blau DM, Denison AM, DeLeon-Carnes M, Adem P, Bhatnagar J, et al. 2009 pandemic influenza a (H1N1): pathology and pathogenesis of 100 fatal cases in the United States. Am J Pathol. 2010;177:166-75.

12. Uiprasertkul M, Kitphati R, Puthavathana P, Kriwong R, Kongchanagul A, Ungchusak K, et al. Apoptosis and pathogenesis of avian influenza a (H5N1) virus in humans. Emerg Infect Dis. 2007;13:708-12.

13. Weinheimer VK, Becher A, Tonnies M, Holland G, Knepper J, Bauer TT, et al. Influenza a viruses target type II pneumocytes in the human lung. J Infect Dis. 2012;206:1685-94.

14. Tan KS, Ong HH, Yan Y, Liu J, Li C, Ong YK, et al. In vitro model of fully differentiated human nasal epithelial cells infected with rhinovirus reveals epithelium-initiated immune responses. J Infect Dis. 2018;217:906-15.

15. Yan Y, Tan KS, Li C, Tran T, Chao SS, Sugrue RJ, et al. Human nasal epithelial cells derived from multiple subjects exhibit differential responses to $\mathrm{H} 3 \mathrm{~N} 2$ influenza virus infection in vitro. J Allergy Clin Immunol. 2016;138(276-281):e215.

16. Forero A, Fenstermacher K, Wohlgemuth N, Nishida A, Carter V, Smith EA, et al. Evaluation of the innate immune responses to influenza and live-attenuated influenza vaccine infection in primary differentiated human nasal epithelial cells. Vaccine. 2017;35:611221.

17. Ioannidis I, McNally B, Willette M, Peeples ME, Chaussabel D, Durbin JE, et al. Plasticity and virus specificity of the airway epithelial cell immune response during respiratory virus infection. J Virol. 2012;86:5422-36.

18. Ito Y, Correll K, Zemans RL, Leslie CC, Murphy RC, Mason RJ. Influenza induces IL-8 and GM-CSF secretion by human alveolar epithelial cells through HGF/c-Met and TGF-alpha/EGFR signaling. Am J Phys Lung Cell Mol Phys. 2015;308:L1178-88.

19. Travanty E, Zhou B, Zhang H, Di YP, Alcorn JF, Wentworth DE, et al. Differential susceptibilities of human lung primary cells to H1N1 influenza viruses. J Virol. 2015;89:11935-44.

20. Pyrc K, Sims AC, Dijkman R, Jebbink M, Long C, Deming D, et al. Culturing the unculturable: human coronavirus HKU1 infects, replicates, and produces progeny virions in human ciliated airway epithelial cell cultures. J Virol. 2010;84:11255-63.
21. Dijkman R, Jebbink MF, Koekkoek SM, Deijs M, Jonsdottir HR, Molenkamp $\mathrm{R}$, et al. Isolation and characterization of current human coronavirus strains in primary human epithelial cell cultures reveal differences in target cell tropism. J Virol. 2013;87:6081-90.

22. Mossel EC, Wang J, Jeffers S, Edeen KE, Wang S, Cosgrove GP, et al. SARS-CoV replicates in primary human alveolar type II cell cultures but not in type I-like cells. Virology. 2008;372:127-35.

23. Dominguez SR, Travanty EA, Qian Z, Mason RJ. Human coronavirus HKU1 infection of primary human type II alveolar epithelial cells: cytopathic effects and innate immune response. PLoS One. 2013;8:e70129.

24. Kebaabetswe LP, Haick AK, Miura TA. Differentiated phenotypes of primary murine alveolar epithelial cells and their susceptibility to infection by respiratory viruses. Virus Res. 2013;175:110-9.

25. Lau SK, Lau CC, Chan KH, Li CP, Chen H, Jin DY, et al. Delayed induction of proinflammatory cytokines and suppression of innate antiviral response by the novel Middle East respiratory syndrome coronavirus: implications for pathogenesis and treatment. J Gen Virol. 2013;94:2679-90.

26. Josset L, Menachery VD, Gralinski LE, Agnihothram S, Sova P, Carter VS, et al. Cell host response to infection with novel human coronavirus EMC predicts potential antivirals and important differences with SARS coronavirus. MBio. 2013;4:e00165-13.

27. Villenave R, Thavagnanam S, Sarlang S, Parker J, Douglas I, Skibinski $\mathrm{G}$, et al. In vitro modeling of respiratory syncytial virus infection of pediatric bronchial epithelium, the primary target of infection in vivo. Proc Natl Acad Sci U S A. 2012;109:5040-5.

28. McNamara PS, Flanagan BF, Hart CA, Smyth RL. Production of chemokines in the lungs of infants with severe respiratory syncytial virus bronchiolitis. J Infect Dis. 2005;191:1225-32.

29. Rosenberger CM, Podyminogin RL, Askovich PS, Navarro G, Kaiser SM, Sanders CJ, et al. Characterization of innate responses to influenza virus infection in a novel lung type I epithelial cell model. J Gen Virol. 2014;95:350-62.

30. VanLeuven JT, Ridenhour BJ, Gonzalez AJ, Miller CR, Miura TA. Lung epithelial cells have virus-specific and shared gene expression responses to infection by diverse respiratory viruses. PLoS One. 2017;12:e178408.

31. Kim TK, Bheda-Malge A, Lin Y, Sreekrishna K, Adams R, Robinson $\mathrm{MK}$, et al. A systems approach to understanding human rhinovirus and influenza virus infection. Virology. 2015;486:146-57.

32.• Stegemann-Koniszewski S, Jeron A, Gereke M, Geffers R, Kroger A, Gunzer M, et al. Alveolar type II epithelial cells contribute to the anti-influenza a virus response in the lung by integrating pathogenand microenvironment-derived signals. MBio. 2016;7:e00276-16 This study characterized the gene expression response of type II alveolar epithelial cells to influenza A virus infection within the context of the lung microenvironment by analyzing gene expression in purified type II cells compared to the whole lung from infected mice.

33. Makris S, Bajorek M, Culley FJ, Goritzka M, Johansson C. Alveolar macrophages can control respiratory syncytial virus infection in the absence of type I interferons. J Innate Immun. 2016;8: 452-63.

34. Channappanavar R, Fehr AR, Vijay R, Mack M, Zhao J, Meyerholz $\mathrm{DK}$, et al. Dysregulated type I interferon and inflammatory monocyte-macrophage responses cause lethal pneumonia in SARS-CoV-infected mice. Cell Host Microbe. 2016;19:181-93.

35. Sharma A, Wu W, Sung B, Huang J, Tsao T, Li X, et al. Respiratory syncytial virus (RSV) pulmonary infection in humanized mice induces human anti-RSV immune responses and pathology. J Virol. 2016;90:5068-74 This study generated a mouse model with functional human lymphocytes that recapitulates characteristics of respiratory syncytial virus infections in humans.

36. Durbin RK, Kotenko SV, Durbin JE. Interferon induction and function at the mucosal surface. Immunol Rev. 2013;255:25-39. 
37. Deonarain R, Alcami A, Alexiou M, Dallman MJ, Gewert DR, Porter AC. Impaired antiviral response and alpha/beta interferon induction in mice lacking beta interferon. J Virol. 2000;74:3404-9.

38. Rudd BD, Luker GD, Luker KE, Peebles RS, Lukacs NW. Type I interferon regulates respiratory virus infected dendritic cell maturation and cytokine production. Viral Immunol. 2007;20:531-40.

39. Price GE, Gaszewska-Mastarlarz A, Moskophidis D. The role of alpha/beta and gamma interferons in development of immunity to influenza a virus in mice. J Virol. 2000;74:3996-4003.

40. Kallfass C, Lienenklaus S, Weiss S, Staeheli P. Visualizing the beta interferon response in mice during infection with influenza A viruses expressing or lacking nonstructural protein 1. J Virol. 2013;87: 6925-30 This study used a reporter mouse system to identify the interferon- $\beta$-producing cells during influenza $A$ virus infection.

41. Bhattacharya J, Westphalen K. Macrophage-epithelial interactions in pulmonary alveoli. Semin Immunopathol. 2016;38:461-9.

42. Hussell T, Bell TJ. Alveolar macrophages: plasticity in a tissuespecific context. Nat Rev Immunol. 2014;14:81-93.

43. Kolli D, Gupta MR, Sbrana E, Velayutham TS, Chao H, Casola A, et al. Alveolar macrophages contribute to the pathogenesis of human metapneumovirus infection while protecting against respiratory syncytial virus infection. Am J Respir Cell Mol Biol. 2014;51: 502-15.

44. Pribul PK, Harker J, Wang B, Wang H, Tregoning JS, Schwarze J, et al. Alveolar macrophages are a major determinant of early responses to viral lung infection but do not influence subsequent disease development. J Virol. 2008;82:4441-8.

45. Tumpey TM, Garcia-Sastre A, Taubenberger JK, Palese P, Swayne DE, Pantin-Jackwood MJ, et al. Pathogenicity of influenza viruses with genes from the 1918 pandemic virus: functional roles of alveolar macrophages and neutrophils in limiting virus replication and mortality in mice. J Virol. 2005;79:14933-44.

46. Zhao J, Zhao J, Van Rooijen N, Perlman S. Evasion by stealth: inefficient immune activation underlies poor $\mathrm{T}$ cell response and severe disease in SARS-CoV-infected mice. PLoS Pathog. 2009;5:e1000636.

47. Narasaraju T, Ng HH, Phoon MC, Chow VT. MCP-1 antibody treatment enhances damage and impedes repair of the alveolar epithelium in influenza pneumonitis. Am J Respir Cell Mol Biol. 2010;42:732-43 This study demonstrated a role for recruited macrophages in promoting repair of the alveolar epithelium during resolution of influenza.

48.• Cardani A, Boulton A, Kim TS, Braciale TJ. Alveolar macrophages prevent lethal influenza pneumonia by inhibiting infection of type-1 alveolar epithelial cells. PLoS Pathog. 2017;13:e1006140 This study identified signaling pathways that alveolar macrophages use to protect type $I$ alveolar epithelial cells from infection by influenza A virus.

49. Becker S, Soukup JM. Airway epithelial cell-induced activation of monocytes and eosinophils in respiratory syncytial viral infection. Immunobiology. 1999;201:88-106.

50.• Chahar HS, Corsello T, Kudlicki AS, Komaravelli N, Casola A. Respiratory Syncytial Virus Infection Changes Cargo Composition of Exosome Released from Airway Epithelial Cells. Sci Rep. 2018;8:387 This study characterized exosomes released from respiratory syncytial virus-infected epithelial cells and demonstrated activation of innate immune responses from monocytes and airway epithelial cells by these exosomes.

51.• Zhou X, Zhu L, Lizarraga R, Chen Y. Human airway epithelial cells direct significant rhinovirus replication in monocytic cells by enhancing ICAM1 expression. Am J Respir Cell Mol Biol. 2017;57: 216-25 This study found that rhinovirus-infected epithelial cells signal for increased expression of rhinovirus receptor protein ICAM1 in monocytes, which promotes infection of these previously resistant cells.
52. Gern JE, Dick EC, Lee WM, Murray S, Meyer K, Handzel ZT, et al. Rhinovirus enters but does not replicate inside monocytes and airway macrophages. J Immunol. 1996;156:621-7.

53.• McNally B, Ye F, Willette M, Flano E. Local blockade of epithelial PDL-1 in the airways enhances T cell function and viral clearance during influenza virus infection. J Virol. 2013;87:12916-24 This study used in vivo and in vitro co-culture models to demonstrate the role of PDL-1 expression by influenza virus-infected epithelial cells in inhibiting $\mathrm{CD8}+\mathrm{T}$ cell functions.

54.• Telcian AG, Laza-Stanca V, Edwards MR, Harker JA, Wang H, Bartlett NW, et al. RSV-induced bronchial epithelial cell PD-L1 expression inhibits CD8+ T cell nonspecific antiviral activity. J Infect Dis. 2011;203:85-94 This study used a co-culture model to demonstrate the role of PDL-1 expression by RSV-infected bronchial epithelial cells in inhibiting $\mathrm{CD8}+\mathrm{T}$ cell functions and viral clearance.

55. Heinecke L, Proud D, Sanders S, Schleimer RP, Kim J. Induction of B7-H1 and B7-DC expression on airway epithelial cells by the tolllike receptor 3 agonist double-stranded RNA and human rhinovirus infection: In vivo and in vitro studies. J Allergy Clin Immunol. 2008;121:1155-60.

56. Stanciu LA, Bellettato CM, Laza-Stanca V, Coyle AJ, Papi A, Johnston SL. Expression of programmed death-1 ligand (PD-L) 1, PD-L2, B7-H3, and inducible costimulator ligand on human respiratory tract epithelial cells and regulation by respiratory syncytial virus and type 1 and 2 cytokines. J Infect Dis. 2006;193:404-12.

57.• Oumouna M, Weitnauer M, Mijosek V, Schmidt LM, Eigenbrod T, Dalpke AH. Cell-contact dependent inhibition of monocytes by airway epithelial cells and reversion by infection with respiratory syncytial virus. Immunobiology. 2015;220:1240-5 This study demonstrated that uninfected bronchial epithelial cells inhibit monocyte activity through direct contact and that these inhibitory effects are overcome by infection of the epithelial cells by RSV.

58. Sung SS, Fu SM, Rose CE Jr, Gaskin F, Ju ST, Beaty SR. A major lung CD103 (alphaE)-beta7 integrin-positive epithelial dendritic cell population expressing Langerin and tight junction proteins. J Immunol. 2006;176:2161-72.

59. GeurtsvanKessel CH, Willart MA, van Rijt LS, Muskens F, Kool $\mathrm{M}$, Baas $\mathrm{C}$, et al. Clearance of influenza virus from the lung depends on migratory langerin+CD11b- but not plasmacytoid dendritic cells. J Exp Med. 2008;205:1621-34.

60. Helft J, Manicassamy B, Guermonprez P, Hashimoto D, Silvin A, Agudo J, et al. Cross-presenting CD103+ dendritic cells are protected from influenza virus infection. J Clin Invest. 2012;122: 4037-47.

61. Lukens MV, Kruijsen D, Coenjaerts FE, Kimpen JL, van Bleek GM. Respiratory syncytial virus-induced activation and migration of respiratory dendritic cells and subsequent antigen presentation in the lung-draining lymph node. J Virol. 2009;83:7235-43.

62. Agrawal S, Srivastava R, Rahmatpanah F, Madiraju C, BenMohamed L, Agrawal A. Airway epithelial cells enhance the immunogenicity of human myeloid dendritic cells under steady state. Clin Exp Immunol. 2017;189:279-89.

63. Hammad H, Chieppa M, Perros F, Willart MA, Germain RN, Lambrecht BN. House dust mite allergen induces asthma via tolllike receptor 4 triggering of airway structural cells. Nat Med. 2009;15:410-6.

64. Demedts IK, Bracke KR, Maes T, Joos GF, Brusselle GG. Different roles for human lung dendritic cell subsets in pulmonary immune defense mechanisms. Am J Respir Cell Mol Biol. 2006;35:387-93.

65.• Unkel B, Hoegner K, Clausen BE, Lewe-Schlosser P, Bodner J, Gattenloehner S, et al. Alveolar epithelial cells orchestrate DC function in murine viral pneumonia. J Clin Invest. 2012;122:3652-64 This study demonstrated that GM-CSF produced by influenza virus-infected epithelial cells activates $\mathrm{CD103}+$ dendritic cells, 
which is required for an effective CD8 $+\mathrm{T}$ cell response and viral clearance.

66. Halstead ES, Umstead TM, Davies ML, Kawasawa YI, Silveyra P, Howyrlak J, et al. GM-CSF overexpression after influenza a virus infection prevents mortality and moderates M1-like airway monocyte/ macrophage polarization. Respir Res. 2018;19:3.

67. Huang FF, Barnes PF, Feng Y, Donis R, Chroneos ZC, Idell S, et al. GM-CSF in the lung protects against lethal influenza infection. Am J Respir Crit Care Med. 2011;184:259-68.

68. Subramaniam R, Mukherjee S, Chen H, Keshava S, Neuenschwander P, Shams H. Restoring cigarette smoke-induced impairment of efferocytosis in alveolar macrophages. Mucosal Immunol. 2016:9:873-83.

69. Hashimoto D, Chow A, Noizat C, Teo P, Beasley MB, Leboeuf M, et al. Tissue-resident macrophages self-maintain locally throughout adult life with minimal contribution from circulating monocytes. Immunity. 2013;38:792-804.

70. Cakarova L, Marsh LM, Wilhelm J, Mayer K, Grimminger F, Seeger W, et al. Macrophage tumor necrosis factor-alpha induces epithelial expression of granulocyte-macrophage colony-stimulating factor: impact on alveolar epithelial repair. Am J Respir Crit Care Med. 2009;180:521-32.

71. Everard ML, Swarbrick A, Wrightham M, McIntyre J, Dunkley C, James PD, et al. Analysis of cells obtained by bronchial lavage of infants with respiratory syncytial virus infection. Arch Dis Child. 1994;71:428-32.

72. McNamara PS, Ritson P, Selby A, Hart CA, Smyth RL. Bronchoalveolar lavage cellularity in infants with severe respiratory syncytial virus bronchiolitis. Arch Dis Child. 2003;88:922-6.

73. Cortjens B, de Boer OJ, de Jong R, Antonis AF, Sabogal Pineros YS, Lutter R, et al. Neutrophil extracellular traps cause airway obstruction during respiratory syncytial virus disease. J Pathol. 2016;238:401-11.

74. Miura TA, Wang J, Holmes KV, Mason RJ. Rat coronaviruses infect rat alveolar type I epithelial cells and induce expression of CXC chemokines. Virology. 2007;369:288-98.

75.• Rzepka JP, Haick AK, Miura TA. Virus-infected alveolar epithelial cells direct neutrophil chemotaxis and inhibit their apoptosis. Am J Respir Cell Mol Biol. 2012;46:833-41 This study demonstrated that CXC chemokine expressed by alveolar epithelial cells upon infection with a rat coronavirus promote chemotaxis of neutrophils and inhibit their apoptosis.

76. Haick AK, Rzepka J, Brandon E, Balemba OB, Miura T. Neutrophils are needed for an effective immune response against pulmonary rat coronavirus infection, but also contribute to pathology. J Gen Virol. 2014;95:578-90.

77.• Deng Y, Herbert JA, Smith CM, Smyth RL. An in vitro transepithelial migration assay to evaluate the role of neutrophils in respiratory syncytial virus (RSV) induced epithelial damage. Sci Rep. 2018;8:6777 This study demonstrated that RSV infection of airway epithelial cells induces migration of neutrophils through the epithelial monolayer, which results in enhanced epithelial damage.

78. Wang K, Lai C, Li T, Wang C, Wang W, Ni B, et al. Basic fibroblast growth factor protects against influenza a virus-induced acute lung injury by recruiting neutrophils. J Mol Cell Biol. 2017;10:573-85.
79. Ying S, O'Connor B, Ratoff J, Meng Q, Mallett K, Cousins D, et al. Thymic stromal lymphopoietin expression is increased in asthmatic airways and correlates with expression of Th2-attracting chemokines and disease severity. J Immunol. 2005;174:8183-90.

80.• Lee HC, Headley MB, Loo YM, Berlin A, Gale M Jr, Debley JS, et al. Thymic stromal lymphopoietin is induced by respiratory syncytial virus-infected airway epithelial cells and promotes a type 2 response to infection. J Allergy Clin Immunol. 2012;130:11871196 e1185 This study demonstrated that RSV induces expression of TSLP by airway epithelial cells, resulting in enhanced immunopathology in mice. They further showed that TSLP expression was increased epithelial cells from asthmatic compared to non-asthmatic children upon RSV infection.

81.• McNamara PS, Fonceca AM, Howarth D, Correia JB, Slupsky JR, Trinick RE, et al. Respiratory syncytial virus infection of airway epithelial cells, in vivo and in vitro, supports pulmonary antibody responses by inducing expression of the $\mathrm{B}$ cell differentiation factor BAFF. Thorax. 2013;68:76-81 This study demonstrated that RSV infection of primary airway epithelial cells or bronchial epithelial cells induces expression of $B$ cell activating factor (BAFF) through an interferon- $\beta$-dependent signaling pathway. This suggests that infected airway epithelial cells may contribute to the generation of antibody responses during viral infection.

82. Reed JL, Welliver TP, Sims GP, McKinney L, Velozo L, Avendano $\mathrm{L}$, et al. Innate immune signals modulate antiviral and polyreactive antibody responses during severe respiratory syncytial virus infection. J Infect Dis. 2009;199:1128-38.

83. Yano T, Mason RJ, Pan T, Deterding RR, Nielsen LD, Shannon JM. KGF regulates pulmonary epithelial proliferation and surfactant protein gene expression in adult rat lung. Am J Phys Lung Cell Mol Phys. 2000;279:L1146-58.

84. Deterding RR, Havill AM, Yano T, Middleton SC, Jacoby CR, Shannon JM, et al. Prevention of bleomycin-induced lung injury in rats by keratinocyte growth factor. Proc Assoc Am Physicians. 1997;109:254-68.

85. Nikolaidis NM, Noel JG, Pitstick LB, Gardner JC, Uehara Y, Wu H, et al. Mitogenic stimulation accelerates influenza-induced mortality by increasing susceptibility of alveolar type II cells to infection. Proc Natl Acad Sci U S A. 2017;114:E6613-22.

86.• Peteranderl C, Morales-Nebreda L, Selvakumar B, Lecuona E, Vadasz I, Morty RE, et al. Macrophage-epithelial paracrine crosstalk inhibits lung edema clearance during influenza infection. J Clin Invest. 2016;126:1566-80 This study demonstrated that cross-talk between IAV-infected epithelial cells, uninfected cells, and alveolar macrophages that drives fluid accumulation in the alveolar compartment during infection.

87.• Korpi-Steiner NL, Valkenaar SM, Bates ME, Evans MD, Gern JE, Bertics PJ. Human monocytic cells direct the robust release of CXCL10 by bronchial epithelial cells during rhinovirus infection. Clin Exp Allergy. 2010;40:1203-13 This study used a co-culture model of bronchial epithelial cells and monocytes to demonstrate synergistic chemokine production during rhinovirus infection. 